\title{
A Versão Brasileira dos Direitos Humanos. Uma Reflexão Política-Antropológica dos PNDHs I e II
}

\author{
Neusa Romero Barazal
}

Resumo: Este ensaio trata do Plano Nacional de Direitos Humanos - PNDH (I e II), criado no Brasil em sua primeira versão em 1996 e complementado em 1999, durante o governo de Fernando Henrique Cardoso. Tratase de um marco importante na história política brasileira no sentido de realinhar a democracia nacional aos moldes democráticos definidos no plano internacional pela Organização das Nações Unidas - ONU. 0 estudo do PNDH (I e II) permite conhecer as propostas e ações governamentais através das políticas públicas adotadas para a proteção e a promoção dos direitos humanos no País, assim como da identificar as práticas de violações desses direitos. Entretanto, estudar direitos bumanos implica localizá-los no tempo e no espaço estabelecendo uma relação entre as histórias universal, particular e singular do homem, tanto sob a visão linear de progresso, quanto da visão cíclica de um processo de construção de um destino comum da humanidade marcadas por antagonismos, disputas e suas superações. Portanto, é objetivo deste trabalho refletir sobre a legitimidade dos Direitos Humanos, enquanto uma proposta de tipo universalizante frente às particularidades sócio-políticas, econômicas e culturais de cada Estado-nacional membro da ONU.

Palavras-chave: Direitos Humanos, PNDH I e II, Universalidade, Cultura e Globalização

Abstract: This assay relates to the Human Rights National Plan which was enacted in Brazil initially in 1996 and complemented subsequently in 1999 (respectively HRNP I and II) under the administration of Fernando Henrique Cardoso. The HRNP represented an important landmark in the recent Brazilian history by promoting an increased alignment of the local democratic principles to the guidelines defined by the United Nations (UN). The study of the HRNP (I and II) allows an understanding of the overarching initiatives and government actions adopted as part of public policies to protect and promote Human Rights in the country as well as the identification of violations. However, the study of Human Rights requires their placement both on time and space in order to establish their relationship with the universal, particular and singular histories of mankind both in the extent of a linear view of progress and a cyclical view of the process of developing a common destiny for mankind, as marked by antagonisms, disputes and its resolutions. Hence it is the objective of this study to discuss the legitimacy of Human Rights as a universal proposition in front of the particular sociopolitical, economic and cultural aspects of each state member of the UN.

Keywords: Human Rights, HRNP I e II, Universality, Culture and Globalization

\footnotetext{
Mestre em Integração da América Latina pelo Programa de Pós-Graduação em Integração da América Latina da Universidade de São Paulo - PROLAM/USP e Doutora em Ciências Sociais na área de Relações Internacionais pela Pontifícia Universidade Católica de São Paulo - PUC-SP.E-mail: barazal@uol.com.br
} 


\section{Introdução}

Estudar Direitos Humanos implica localizá-los no tempo e no espaço, estabelecer uma relação entre eles e a história universal do homem sob a visão linear de progresso, sob a visão cíclica de um processo de construção de um destino comum da humanidade, ou sob ambas as visões, marcadas por antagonismos, disputas e suas superações. Nesse sentido, Immanuel Kant (2003), em Idéia de uma história universal de um ponto de vista cosmopolita, escrito em 1784, propôs a existência de uma história do mundo (Weltgeschichte) possuidora de um fio condutor a priori, que obedece a finalidades de uma Natureza regulada por leis naturais, na maioria das vezes ignoradas pelo próprio homem. No entanto, ao fazer tal afirmação Kant não exclui a possibilidade de elaboração empírica da história do mundo, mas lhe fornece um sentido, uma finalidade universais. Segundo o autor,

pode-se considerar a história da espécie humana, em seu conjunto, como a realização de um plano oculto da natureza para estabelecer uma constituição política (Staatsverfassung) perfeita interiormente e, quanto a este fim, também exteriormente perfeita, como o único estado no qual a natureza pode desenvolver plenamente, na humanidade, todas as suas disposiçôes (KANT, 2003, p. 17).

Por decorrência, Kant pensa a constituição política em sua forma perfeita, dentro das perspectivas humanas, como aquela que admite a liberdade civil onde a todos é permitida a liberdade, sob a orientação de leis comuns que superam o esboço dos Estados modernos, realizada em um Estado cosmopolita universal, "como o seio no qual podem se desenvolver todas as disposições originais da espécie humana” (KANT, 2003, p.19). Portanto, com este espírito, ou seja, o de uma antropologia política que se quer pensar o presente ensaio sobre os Direitos Humanos no mundo e, especificamente, sua manifestação no Brasil.

Nesse caso, importa acompanhar as tentativas filosóficas e empíricas empreendidas pela Organização das Naçôes Unidas - ONU, aonde a união civil da espécie humana vem sendo considerada possível e mesmo favorável desde que sejam observados os princípios e proposições estabelecidos pelos Direitos Humanos, assim como a efetiva legitimação desse discurso perante os Estados - membros e, especificamente, pelo governo brasileiro que ao ratificar diversos tratados internacionais decide criar e implantar, desde 1996, o Plano Nacional de Direitos Humanos - PNDH I e II. Com esta atitude, o Brasil demonstra não somente um comprometimento político-filosófico favorável à causa dos Direitos Humanos, mas avança no sentido da sua aplicabilidade quando adota uma política publica voltada para a efetivação desse tipo de direito entendido, no plano internacional, como uma possibilidade de realização da finalidade universal do homem. 


\section{Esclarecimentos sobre os PNDHs I e II}

Dessa maneira, a atenção deste ensaio se concentra no Plano Nacional de Direitos Humanos - PNDH, criado no Brasil em 1996 e complementado em 1999, durante o governo de Fernando Henrique Cardoso, por representar o primeiro programa no gênero lançado na América Latina, um marco importante na história política brasileira no sentido de realinhar a democracia nacional aos moldes defendidos no plano internacional pela Organização das Nações Unidas - ONU. Portanto, os PNDHs I e II permitem verificar as propostas e ações governamentais através de uma política voltada para proteção e promoção dos Direitos Humanos, e avaliar como o governo tem agido para conciliar democracia com as sérias injustiças sociais, historicamente manifestas por exclusões sociais e pelas violações constantes dos Direitos Humanos no País.

Assim, as proposiçôes dos os PNDHs I e II servem para contrastar com a falta de desenvolvimento no País em termos civis, políticos, econômicos, sociais e culturais. Nesse sentido, eles se transformam numa espécie de referência e orientação para a concretização de um projeto político que visa o acesso aos brasileiros a esse tipo de direito. Diz-se isso porque a tarefa dos PNDHs I e II reside em transformar os Direitos Humanos, base ética da vida social moderna, estabelecida pela Organização das Nações Unidas - ONU, em valor antropológico assimilado pela consciência coletiva brasileira, legitimado através da defesa, promoção e concretização dos mesmos pela via político-jurídica, econômica social e cultural. Em outras palavras, os PNDHs I e II se apresentam como fenômeno de intermediação entre as perspectivas ideais de uma liberdade civil universal, defendidas no plano internacional e a complicada realidade da vida social e econômica brasileira.

Para melhor conhecer os PNDHs I e II, cabe uma breve explanação a respeito da sua delimitação, situação e forma, por entendê-las como dados definitivos para proceder à sua análise e interpretação.

Quanto ao primeiro aspecto, o da sua delimitação, os PNDHs I e II significam uma iniciativa governamental brasileira de realizar o viés democrático previsto na Constituição promulgada em 1988. No entanto, para lograr êxito, serão necessárias inúmeras reformas de caráter estrutural que viabilizem governo e sociedade no projeto de proteção e promoção efetivas dos Direitos Humanos no País. Muitas das medidas políticas propostas nos PNDHs I e II, dependem de decisōes tomadas no plano nacional e no internacional para que serem ativadas. Para exemplificar, no plano internacional, pode-se destacar os compromissos assumidos pelo Estado brasileiro, membro da Organização das Nações Unidas, frente aos tratados internacionais de Direitos Humanos, que foram aprovados pelo Congresso Nacional; no plano nacional, a Constituição Brasileira de 1988 tem representado um marco importante quanto à incorporação política e jurídica de proteção aos Direitos Humanos. No entanto, faz-se necessário refletir sobre questōes como: 
- no plano internacional, de que forma a existência e implantação dos PNDHs I e II no Brasil inserem o País no diálogo democrático internacional?;

- no plano nacional, em que sentido o PNDH I auxilia na democratização da sociedade brasileira ao centrar-se na promoção dos direitos civis e políticos? Até que ponto o PNDH II influencia estratégias de desenvolvimento econômico, social e cultural para o Brasil?

- no plano que concerne aos indivíduos, por que os Direitos Humanos são reduzidos e classificados, segundo domínio popular, em "abstrações jurídicas, de atentado à segurança e aos interesses nacionais, de defesa de bandidos”? (RESENDE, s.d, p. 62).

Acredita-se que com o aprofundamento dessas questôes, amplia-se a compreensão sobre a função e o desempenho dos PNDHs I e II na sociedade brasileira e verifica-se a sua validade como instrumento de democratização. Portanto, a delimitação dos PNDHs I e II se apresenta, num primeiro momento, dependente de dispositivos político-juridicos que the delineiam os contornos formais e ideais que são ampliados a partir dos impactos causados pelo confronto provocado por sua idealidade e a realidade concreta internacional, nacional e individual.

Quanto ao segundo aspecto selecionado, aquele que diz respeito à situação dos PNDHs I e II no contexto histórico atual, pode-se dizer que ela representa uma postura política ambiciosa ao pretender harmonizar o discurso sobre democracia em efetiva cidadania nacional orientando-se pelos parâmetros internacionais. Desse modo, para alcançar tais objetivos necessita-se de esforços conjuntos envolvendo os governantes brasileiros; as Organizações Não Governamentais - ONGs - e a população em geral, comprometidos com a causa porque, não basta vontade política, é preciso haver o envolvimento de diferentes instâncias da sociedade brasileira no sentido de tirar os Direitos Humanos do papel e transformá-los em instrumento efetivo no atendimento das necessidades concretas da população. Portanto, a atitude política do governo brasileiro permite que o País se afine com a modernidade desde que ela seja cada vez mais efetiva e legitimamente observável junto 'a população nacional.

O terceiro aspecto, aquele que contempla a forma dada aos Direitos Humanos, nos PNDHs I e II, se revela com um forte conteúdo constitucional, associado pelo Estado de direito brasileiro, e, também, com a constatação de sua formalização legal como o reconhecimento de necessidades reais. Em outras palavras, o formato adotado na construção dos PNDHs I e II, priorizaram a formalidade legal (simbólica) visando interferir, por essa via, sobre a realidade (concreta) da vida da sociedade. Em outras palavras, circunscreveram-se as açōes políticas, num primeiro momento (PNDH I), a objetivos de curto, médio e longo prazos, e, num segundo momento (PNDH II), devido às dificuldades de efetivação do Plano, a uma reestruturação das atividades a partir de um conjunto de planos de ações 
anuais, definidores das medidas a serem adotadas com referência aos recursos orçamentários destinados a financiá-las, assim como a criação de órgãos responsáveis por sua execução. Portanto, se percebe uma evolução na formatação do Plano ao ser consideraradas suas duas versões, ou seja, a de 1996 complementada com a de 1999 que permitiu a destinação de recursos financeiros para atender demandas de organismos políticos federais, estaduais, municipais e particulares efetuadas por meio de convênios, para o atendimento das necessidades prescritas nos PNDHs I e II.

Pode-se dizer que os caracteres correspondentes à delimitação, situação e forma dos PNDHs I e II, que priorizaram, num primeiro momento, seu caráter ideal devido ao tipo de estruturação racionalista, baseia-se:

- na existência de uma sociedade capaz de conciliar-se consigo mesma através de um contrato legal;

- na multiplicidade de atividades sociais que devem ser transparentes entre si, capazes de traduzir a maneira de ser racionalizada pelo direito e consolidadas pelo Estado; e,

- no fato de que o Estado esteja encarregado de exercer a promoção democrática da sociedade, do povo e da nação, respeitando a livre manifestação da vontade coletiva.

Em outras palavras, a esta estratégia típica da modernidade, percebe-se a possibilidade da manutenção do status quo do sistema estatal, pela via das reformas do direito que, por sua vez, permitem, segundo Lefort (1994), a utilização de um poder racional, conciliador da autoridade com as iniciativas coletivas, segundo critérios conformados com as decisões de Estado.

Estruturalmente o modelo político derivado dos Direitos Humanos, através dos PNDHs I e II, fortalece o Estado brasileiro como intermediário entre o modelo e a realidade, reforçando uma postura democrática por defender os direitos fundamentais inerentes à sociedade; por antecipar reivindicações de novos direitos; por transformar-se numa espécie de via ou instrumento de resistência política popular; por permitir que se estabeleçam motivos de lutas de diferentes tipos de movimentos como, por exemplo, os ecológicos, os anti-nucleares, os anti-racistas, os dos sem-terra, os feministas, os homossexuais, os dos grupos indígenas, os das minorias em geral; e, consequentemente por inserir o País no internacionalismo que postula uma espécie de cidadania ampliada.

\section{A questão do Estado e a do internacionalismo}

No cenário denominado globalização em que aparecem os PNDHs I e II, o despertar do internacionalismo, defensor da cidadania ampliada, se depara com: 
enormes atrasos e paralisias sob o efeito dos localismos e provincialismos [sic]. A unidade intersolidária do planeta não se tornou uma unidade de sociedade (das naçôes), e, embora haja doravante uma comunidade de destino, ainda não há a consciência comum dessa Schicksalgemeinschaft' (MORIN; KERN, 2003, p. 42).

Conseqüentemente, questiona-se a legitimidade dos Direitos Humanos enquanto proposta de tipo universalizante frente às particularidades culturais, políticas, sociais e econômicas típicas de cada sociedade (Estado-nacional). A tentativa de racionalizar um discurso humanitário internacional defensor dos Direitos Humanos se depara com múltiplos outros discursos culturais, derivados de experiências históricas únicas, que nem sempre se conformam com a política estatal adotada na modernidade. Por exemplo, há a discussão que ao definir os Direitos Humanos como Direitos Naturais ou Fundamentais do homem, classificam-nos por direitos universais ${ }^{2}$. Para tanto, "el derecho natural clásico parte de la idea de un orden natural, de un cosmos perfectamente ordenado" (ROSLER, 1993, p. 25). Desse modo, pensar os direitos segundo a perspectiva do direito natural, implica pensá-los como algo já existente, não inventado e que necessita apenas ser reconhecido pelo homem. Desde esse ponto de vista, os Direitos Humanos como Direitos Naturais ou Fundamentais do homem, quando adaptados à modernidade, passam a representar uma espécie de instrumento necessário e legítimo para o efetivo exercício democrático dos e entre os povos através da

\footnotetext{
${ }^{1}$ Schicksalgemeinschaft. Comunidade de destino.

${ }^{2}$ Universalização. "passagem do particular ou do individual ao universal. '0 sinal característico deste período (aquele em que a reflexão começa a aplicar-se aos preceitos morais para legitimar aos olhos da razão) é a universalização dos princípios da moral' (LEVY-BRUHL apud LALANDE, 1999, p. 1174). Uma das características mais marcantes na espécie humana é o fato de desenvolver cultura. Isto acontece porque o homem necessita viver em acordo com a natureza, mas recria uma "segunda" natureza expressa através dos meios culturais que são determinantes da vida social. Essas manifestações culturais proporcionam significado à vida do homem, assim como fornece regras de ação coletivas responsáveis pela convivência social, porém, muitas são as formas de entendimento dadas à cultura e, dentre elas, pensadores como Gramsci, Geertz, Parsons e Althusser, defendem posições idealistas e costumam dizer que "uma sociedade é coesa porque as normas são compartilhadas" (OUTHWAITE, 1993, p. 164). Tal posicionamento tende a resultar em um relativismo cultural que, se levado a extremos, pode resultar na negação da função científica de criar leis universais, cabendo-lhe apenas a função de tradutora e de mediadora entre mundos distintos. Por outro lado, existem os pensadores materialistas que "vêem as ideologias como véus ou máscaras para grupos de interesses; ainda mais importante, tendem a acreditar que a maioria dos agentes tem plena consciência de seus próprios interesses e, de acordo com isso não têm probabilidades de engolir crenças que os poderosos tentam impingir-lhes" (OUTHWAITE, 1993, p. 164). Dentre os defensores dessa segunda posição encontram-se intelectuais marxistas e alguns da escola neoclássica de economia. ${ }^{3}$ Tradução: o direito natural clássico parte da idéia de uma ordem natural, de um cosmos perfeitamente ordenado.
} 
interferência do Estado - desde que este harmonize seu ordenamento jurídico aos princípios defendidos pelos Direitos Humanos. Mas, segundo Lefort (1994), se existem direitos inerentes à natureza humana, como defini-la?

Segundo o autor, para responder a essa questão deve-se saber que, primeiro, à natureza corresponde tudo o que é inato, instintivo e espontâneo. Assim sendo, pode-se tirar um ensinamento sobre a natureza do homem que, além dos aspectos biológicos de sua constituição, existem componentes culturais, responsáveis por aquilo que é adquirido pela experiência individual ou social. Segundo, se as leis da natureza servem de princípio fundamental para formar juízos normativos, então, as leis humanas podem tomá-las como instrumento de imitação. Terceiro, por decorrência, notar-se-á que a natureza do homem permanece como definição que nunca abandonou as premissas do pensamento clássico, que perseguiu o pensamento moderno, cujo aprofundamento se deu sob o efeito das contradições engendradas pela ciência positiva e pelo historicismo. Assim, a ciência positiva e o historicismo se transformam em requisitos necessários a serem utilizados na compreensão das contradições existentes entre os Direitos Humanos, naturais e universais, e as diversidades culturais, históricas e particulares.

Complementando tais colocações, pode-se acrescentar aquela defendida por Kant (2003), que diz: "toda cultura e toda arte que ornamentam a humanidade, a mais bela ordem social são frutos da insociabilidade, que por si mesma é obrigada a se disciplinar e, assim, por meio de um artifício imposto, a desenvolver completamente os germes da natureza" (KANT, 2003, p. 11). Desse modo, a natureza humana manifesta por meio de uma espécie de "insociabilidade" que, para ser disciplinada, necessita submeter-se a leis que auxiliem o homem a superar sua inclinação exclusivista e levá-lo a conviver com seus semelhantes em uma sociedade civil.

Na seqüência dessa discussão sobre a legitimidade dos Direitos Humanos, acrescentase que, do mesmo modo que diversidade cultural aparece como contraponto à universalidade dos Direitos Humanos, para Karl Marx (2003), a emancipação política do homem, pertencente à sociedade política moderna, seria uma ilusão por encontrar-se distante da real emancipação humana. Para tanto, ele afirma que o homem teria de superar sua redução a um ser egoísta, independente, membro da sociedade burguesa, de um lado, e também de um cidadão de estado, enquanto pessoa abstrata, para alcançar sua real e verdadeira emancipação, a humana. Por esses motivos, os Direitos Humanos não são tidos por Marx como sendo direitos inatos, mas uma construção idealizada para defender os valores burgueses no plano internacional.

A partir do argumento de Marx e de observações históricas, Lefort (1994), chama a atenção para a posição assumida pelos seus herdeiros que - frente à concentração de força do Estado na União Soviética, difundida pelas vítimas do Gulag, por Soljenitsin, pelos 
dissidentes dos Estados socialistas, que reclamavam o respeito aos direitos do homemforam levados a mudar seus espíritos frente aos Direitos Humanos, no sentido de considerálos como direitos que possuíam um valor em si mesmos, apesar do quadro da democracia burguesa. Desde então, passando a defender que a instauração do socialismo deveria assumi-los como salvaguarda, mesmo porque esses direitos não lhes parecem formais e investidos da intenção de ameaçar o papel exercido pelo Estado.

Ainda a respeito da legitimidade dos Direitos Humanos, no caso brasileiro, pode-se pensar que o Estado nacional assimila e adota a visão universalista quando cria os PNDHs I e II. Parte disso deve-se ao compromisso existente entre os países-membro da ONU, dentre eles o Brasil, de honrar tratados firmados no plano internacional de Direitos Humanos, transformando-os, através de legislaçōes internas, em instrumentos jurídicos constitucionais conformados aos modernos padrões democráticos. No entanto, se, paralelamente a esse compromisso, a realidade nacional brasileira apresenta profundas diferenças sociais, políticas e econômicas, então os PNDHs I e II têm um papel fundamental a desempenhar no sentido de minimizar esses contrastes. Daí a defesa de uma política de educação para os Direitos Humanos, endereçada à população em geral através de suas lideranças políticas, seus partidos, representantes do poder judiciário, personalidades da vida intelectual, cultural, e representantes dos meios de comunicação, visando a transformálos em direitos efetivamente reconhecidos, defendidos e reivindicados pela população como um todo, ou seja, incorporados pela cultura nacional. Nesse processo de mudança social e de adoção de nova mentalidade, tanto a universalidade quanto a particularidade dos Direitos Humanos se apresentam como básicos e necessários.

No entanto, deve-se considerar que esse tipo de política somente logrará êxito desde que exista a preocupação e sensibilidade de perceber que aos direitos políticos dos cidadãos deve-se acrescentar seus direitos econômicos e sociais, sob pena de comprometer a democracia. Para tanto, são essenciais as preocupações com as questôes sócio-econômicas de boa parte da população excluída. Assim sendo, a sociedade ao conhecer seus direitos e obrigações enquanto cidadãos, deve exigir e cobrar das autoridades governamentais decisões de caráter estrutural envolvendo medidas políticas, econômicas, sociais e culturais capazes de, por exemplo, encaminhar o problema do desemprego, da educação, da saúde, criando oportunidades de trabalho, de renda, de conscientização política e de bem-estar para a população como meio de viabilização da sua cidadania ampliada e universal. Assim, a educação, a saúde e o trabalho vem sendo considerados requisitos mínimos e necessários para a promoção, no Brasil, de uma vida com dignidade como a que é proposta pelos Direitos Humanos e pela ONU.

Sobre isso, o posicionamento assumido pelo Estado brasileiro, sob o governo de Fernando Henrique Cardoso, dispôs nos Planos a adoção de políticas sociais estruturadas 
em torno de dois objetivos: "oferecer mais e melhores serviços sociais básicos e atuar para aumentar as oportunidades de trabalho e renda" (BRASIL, 1996a, p. 42). Para tanto, acentuando a conjugação de dois fenômenos que norteiam tanto a ação da economia quanto do setor público que são:

o crescimento econômico no sentido de assegurar a criação de empregos, a eliminação da pobreza e a elevação do nível de renda da população, e prioridade governamental à área social de modo a garantir a distribuição justa dos frutos desse crescimento e a preparar as geraçōes futuras para um país moderno e exigente quanto à qualificação intelectual de seus habitantes ativos (BRASIL, 1996, p. 42).

Ratificando essas idéias, Piovesan (2003, p. 105), diz que a violação aos direitos econômicos, sociais e culturais exige prioridade governamental no sentido de implementar políticas públicas que submetam tanto o Governo como organismos financeiros internacionais a tomar decisões para resolver problemas econômicos que condenam a população ao empobrecimento, ao desemprego e à fome. Sabe-se que a realização deste direito é de tipo progressiva, o que não impede que tenham primazia pelos Estados. Neste sentido, ela acrescenta que outros agentes necessitam ser responsabilizados pelo agravamento das questôes econômico-sociais das populações pobres mundiais e eles pertencem ao setor privado, principalmente as multinacionais ${ }^{5}$, principais beneficiárias do processo de globalização. Mas, diz também que este tipo de questão deve ser encaminhado pela Assembléia das Naçôes Unidas para convencê-las a adotar códigos de Direitos Humanos relativos à atividade de comércio, dentre outras medidas sancionais.

\section{Sobre direitos humanos e os PNDH I e II}

Este ensaio pretende realizar uma reflexão a respeito dos métodos e instrumentos adotados pela Organização das Nações Unidas e, em decorrência, pelo Brasil na implementação, na proteção e na promoção dos Direitos Humanos. Nesse sentido, serão

\footnotetext{
${ }^{4}$ "Embora as agências financeiras internacionais estejam vinculadas ao sistema das Nações Unidas, na qualidade de agências especializadas, o Banco Mundial e o Fundo Monetário Internacional, por exemplo, carecem da formulação de uma política vocacionada aos direitos humanos. Tal política é medida imperativa para o alcance dos propósitos da ONU e, sobretudo, para a coerência ética e principiológica que há de pautar sua atuação. A agenda de direitos humanos deve ser, assim, incorporada no mandato de atuação destas agências". (PIOVESAN, 2003, p. 106-107).

5 "das 100 (cem) maiores economias mundiais, 51 (cinqüenta e uma) são empresas multinacionais e 49 (quarenta e nove) são Estados-nacionais" (PIOVESAN, 2003, p. 108).
} 
enfocados, primeiramente, os critérios de viabilização de tipo jurídico-estatale, segundo, os referentes à via da antropologia cultural aplicada utilizando o método funcionalista e a teoria das necessidades de Bronislau Malinowski.

\subsection{Direitos humanos: sob a ótica jurídico-estatal}

Os Direitos Humanos, quando apresentados de forma cronológica informam sobre sua vocação natural como princípio filosófico universal até atingir o estágio de direito positivo. Nesse percurso é possível apreciar seu aparecimento, evolução e adoção pelos países-membro da ONU e considerar que durante os primeiros cinqüenta anos de sua existência não contaram com eficientes dispositivos legais de coerção para sua defesa. Por conta disso, foram sendo criados mecanismos de valorização jurídica dos Tratados Internacionais, assim como de proteção internacional dos Direitos Econômicos, Sociais e Culturais, chegando-se à estruturação de um Tribunal Penal Internacional ${ }^{6}$, tudo isso atrelando Direitos Humanos à responsabilidade dos Estados na consolidação de uma cidadania democrática ampliada.

A justificativa encontrada para a criação de um Tribunal Penal Internacional deu-se devido as constatações de que os Direitos Humanos se mantiveram à margem da vida corrente de populações em diversas Nações, constituídas como Estados e membros da ONU, o que representava uma contradição entre o discurso e as açōes assumidas pelos mesmos. Desse modo, passou-se a considerar urgente a sua introdução no cotidiano desses indivíduos sabendo-se, de antemão, das dificuldades que isso representaria frente aos interesses de oligarquias políticas e econômicas ameaçadas.

Portanto, transcorridos 50 anos de existência e enfrentando crises de credibilidade devido às barreiras encontradas para convencer a comunidade internacional sobre o seu projeto, a ONU criou mecanismos de coação, semelhantes aos praticados pelos Estadosmembros, como o Tribunal Penal Internacional, que objetiva enfrentar os abusos praticados contra pessoas e minorias sociais excluídas do projeto de democratização global. Dessa maneira, foram assimilados os mesmos conceitos de policia e de segurança, interpretados como conceitos sociais da sociedade burguesa, para dar garantias aos Tratados, às pessoas, aos seus direitos e às suas propriedades.

A atitude de instituir o Tribunal, interpretada como uma vitória conquistada pela ONU, visa garantir sua própria manutenção como entidade fundada para defender a

\footnotetext{
${ }^{6}$ "em 11 de abril de 2002, o Estatuto de Roma, que cria o Tribunal Penal Internacional, alcançou a ratificação de 66 Estados, ultrapassando, assim, o consenso mínimo necessário para a sua entrada em vigor" (PIOVESAN, 2003, p. 147).
} 
paz mundial, assim como, à grande parcela da população mundial de excluídos; ela serve como alerta para o sistema de Estado de direito, no que diz respeito às práticas de abusos de poder realizados em nome da defesa da autonomia e da unidade nacionais. Com ele, a ONU, entidade supranacional, adquire força para cobrar e lembrar os Estados-membros sobre seus papéis e responsabilidades.

\subsection{Direitos Humanos pela via da antropologia cultural aplicada}

Na seqüência, os Direitos Humanos, entendidos como sendo um fenômeno que se encontra entre a norma jurídica positiva e o conjunto de valores culturais de diferentes nacionalidades pode ser analisado através de argumentos emprestados da Antropologia. Sob esse aspecto, os PNDHs I e II, quando relacionados à realidade cultural brasileira, permitem pensar a questão funcional dos Direitos Humanos como necessidade real da população. Considera-se a leitura feita por Brelet (1995), para este procedimento analítico, o viés adotado é o da antropologia cultural aplicada que toma como referencial teórico, a proposta do funcionalismo de Malinowski, cujo método vem sendo utilizado pela própria $\mathrm{ONU}$, auxiliada por profissionais e teóricos da antropologia no trato das questôes da diferença cultural no plano da sociedade globalizada.

Assim sendo, cabe esclarecer que o funcionalismo repousa sobre três postulados interdependentes, a saber:

- o da unidade funcional da sociedade;

- o do funcionalismo universal onde todos os elementos sociais ou culturais padronizados têm funçōes positivas;

- o da necessidade significando que, " 1 - certas funções são necessárias à vida da sociedade (ou de um grupo, ou de um indivíduo) e que, 2- certas formas sociais ou culturais são necessárias (portanto insubstituíveis) para a realização dessas funçōes" (LALLEMENT, 2004, p.133-4).

Desse modo, o funcionalismo de Bronislaw Malinowski, é um dos modelos teóricos adotado pela Organização das Nações Unidas - ONU, no sentido de orientar suas ações no tratamento das questóes concernentes às diferentes realidades culturais dos seus Estados-membros, sendo compreendido como a teoria segundo a qual a cultura deve ser considerada como a resposta de uma comunidade às suas necessidades essenciais ou básicas, no seu desenvolvimento específico. Por isso, o modelo funcionalista permite considerar a importância das manifestações das particularidades contingentes de cada caso, a partir de uma interpretação de caráter universalista. Vale lembrar que a análise funcionalista tenta romper com as filosofias evolucionistas da história e é devedora da 
biologia por identificar a sociedade como um todo cujas partes desempenham uma função necessária para o equilíbrio do conjunto. Sua hipótese central diz que

\begin{abstract}
se as necessidades comuns a todos os seres humanos formam invariantes naturais, cada sociedade organiza a seu jeito o seu tratamento cultural (...) esse jeito de organizar a vida social gera necessidades derivadas (educação, pesquisa, artes, religião, direito e moral) que, embora sejam irremediavelmente específicos a cada cultura, estão sempre ligados por uma relação instrumental aos imperativos orgânicos (necessidade de sobreviver, de se manter bem de saúde...) (MALINOWSKI apud LALLEMENT, 2004, p. 112).
\end{abstract}

Em sua obra, Malinowski (1986, p. 171-172), destaca por objeto de estudo a cultura e sugere como axiomas gerais do funcionalismo que: a cultura é essencialmente, um aparato instrumental porque através dela o homem em seu ambiente enfrenta problemas concretos para a satisfação de suas necessidades; é um sistema de objetos, atividades e atitudes que convergem para um fim; é uma totalidade devido a interdependência existente entre seus elementos; que se organiza em instituiçôes como a família; o clă; a comunidade local, a tribo, as atividades políticas, legais, educacionais e de cooperação econômica. Sob o ponto de vista dinâmico, a cultura é analisada por diferentes aspectos como a educação, controle social, economia, sistema de conhecimentos, crenças, moral, modos de expressão criativa e artística. Definido isso, percebe-se que o funcionalismo examina os fenômenos sociais e as instituições nas suas relações com o corpo social de que fazem parte. Seu sentido se revela somente a partir dessas relaçôes funcionais com outros fenômenos e instituições.

Melhor esclarecendo, Malinowski, adepto do funcionalismo e da teoria das necessidades percebeu que na análise das organizaçôes sociais, as necessidades essenciais ou básicas transformam-se em instituiçôes, adquirindo contorno de necessidades secundárias ou derivadas das primeiras, dentro de sua dinâmica e processo específicos. Portanto, para ele as instituiçôes sociais variam seu conteúdo valorativo, de cultura para cultura, porém, sua essência permanece a mesma, fundamentando desse modo o argumento da universalidade.

O método de análise preconizado por Malinowski leva em conta um dos princípios fundamentais do seu paradigma segundo o qual os grupos de variáveis podem se modificar simultaneamente, em função da dinâmica criada pelas necessidades. A título de ilustração, serão apresentados quadros para visualizar os procedimentos adotados pela ONU a partir da orientação da teoria das necessidades: 


\begin{tabular}{|c|c|c|}
\hline \multicolumn{3}{|c|}{$\begin{array}{c}\text { Quadro I } \\
\text { A teoria de Malinowski e as agências especializadas da ONU }\end{array}$} \\
\hline \multicolumn{2}{|c|}{ MALINOWSKI } & ONU \\
\hline $\begin{array}{c}\text { Necessidades } \\
\text { essenciais ou básicas }\end{array}$ & Respostas culturais & Agências especializadas \\
\hline Metabolismo & Subsistência & $\mathrm{FAO}^{7}$ \\
\hline Reprodução & Parentesco & OMS $^{8}$, UNICEF ${ }^{9}$, UNPF \\
\hline Bem estar corporal & Abrigo/habitação & UNCHS (1976) \\
\hline Segurança & Proteção & OMS, PNUE (1972) \\
\hline Movimento & Atividades & $\mathrm{BIT}^{10} / \mathrm{OIT}^{11}, \mathrm{UNESCO}^{12}$ \\
\hline Crescimento & Educação & OMS, UNESCO \\
\hline $\begin{array}{l}\text { Fonte: Utopie et Fonda } \\
\text { Anthropologie de l'ON }\end{array}$ & $\begin{array}{l}\text { es Nations Unies. In } \\
5 \text {, p. } 95\end{array}$ & ELET, Claudine. \\
\hline
\end{tabular}

Satisfazer as necessidades essenciais ou básicas é considerado um meio prioritário de instaurar melhores condições de vida às populações mundiais e, segundo Brelet (1995), desde que se deu a criação da ONU, ela tem organizado suas atividades seguindo um padrão que corresponde, de uma parte, a teoria de Malinowski e, de outra, as prioridades que a Segunda Guerra tinha gerado no mundo. Dessa maneira, o Quadro I possibilita identificar que a Organização do sistema da ONU corresponde exatamente aos determinantes universais que são necessidades essenciais ou básicas, assim como as prioridades correspondentes que devem servir de base aos Estados membros da ONU.

\footnotetext{
FA0 - Organização para a Alimentação e a Agricultura, fundada em 16 de outubro de 1945;

${ }^{8}$ OMS - Organização Mundial da Saúde, fundada em junho de 1946;

${ }^{9}$ UNICEF - Fundo das Nações Unidas para a Infância, fundada em dezembro de 1946;

${ }^{10}$ BIT - Bureau Internacional do Trabalho

${ }^{11}$ OIT - Organização Internacional do Trabalho, fundada em 1946;

${ }^{12}$ UNESCO - Organização das Nações Unidas para a Educação, a Ciência e a Cultura, fundada em novembro de 1946.
} 


\section{Quadro II}

A teoria de Malinowski e o Bureau Internacional do Trabalho (ONU)

\begin{tabular}{|c|c|c|}
\hline \multicolumn{2}{|c|}{$\begin{array}{l}\text { MALINOWSKI } \\
(1929-1942)\end{array}$} & $\begin{array}{c}\text { BUREAU } \\
\text { INTERNACIONAL DO } \\
\text { TRABALHO }{ }^{13}\end{array}$ \\
\hline $\begin{array}{c}\text { Necessidades } \\
\text { elementares ou } \\
\text { básicas }\end{array}$ & Respostas culturais & Necessidades especiais \\
\hline Metabolismo & Subsistência & Alimentação \\
\hline Reprodução & Parentesco & Saúde \\
\hline Bem estar corporal & Abrigo/habitação & Alojamento/vestimenta \\
\hline Segurança & Proteção & Saúde \\
\hline Movimento & Atividades & Transportes \\
\hline Crescimento & Educação & Possibil. de instrução \\
\hline Saúde & Higiene & Água potável/saneam. \\
\hline
\end{tabular}

De modo similar ao quadro anterior, o Quadro II sugere que identificar as prioridades constitui meio fiável de medir o nível de bem-estar real das populações concernentes. Esta avaliação permite julgar os resultados de uma política, quaisquer que sejam os argumentos ideológicos dos poderes em questão, levando em conta os particularismos locais, as necessidades essenciais ou básicas, constituintes dos determinantes universais.

Nesse sentido, o BIT reparte esta reorientação em dois conjuntos. Ele desenha o primeiro - que corresponde às necessidades elementares ou básicas descritas por Malinowski - como "as condições mínimas de consumo privado", tendo por princípio que "a satisfação das necessidades supõe que sejam cumpridas efetivamente as condições mínimas de consumo privado por uma família”. O segundo conjunto de elementos corresponde às necessidades que Malinowski designa como secundárias ou derivadas respostas cultu-

\footnotetext{
${ }^{13}$ BIT - Bureau Internacional do Trabalho, estabelecido em Genebra, é o secretariado permanente da Organização Internacional do Trabalho e prepara os acordos que servem de base aos trabalhos deste último.
} 
rais, entendidas pelo BIT como sendo necessidades essenciais para demonstrar sua preocupação com a melhoria das condições de vida e de trabalho no mundo inteiro. Assim, as necessidades essenciais compreendem os serviços de base às vezes fornecidos e utilizados pela coletividade em seu conjunto - dos quais o acesso à água potável, aos sistemas de evacuação dos esgotos, dos meios de transporte público, dos serviços sanitários e das possibilidades de instrução, etc.

\begin{tabular}{|c|c|c|}
\hline \multicolumn{3}{|c|}{$\begin{array}{l}\text { Quadro III } \\
\text { A teoria de Malinowski e a Organização Mundial } \\
\text { de Saúde - OMS e a UNICEF (ONU) }\end{array}$} \\
\hline \multicolumn{2}{|c|}{$\begin{array}{l}\text { MALINOWSKI } \\
(1929-1942)\end{array}$} & $\begin{array}{l}\text { O.M.S - UNICEF } \\
\qquad(1978)\end{array}$ \\
\hline $\begin{array}{l}\text { Necessidades } \\
\text { elementares ou } \\
\quad \text { básicas }\end{array}$ & Respostas culturais & Cuidados de saúde primários \\
\hline Metabolismo & Subsistência & Alimentação/nutrição \\
\hline \multirow[t]{2}{*}{ Reprodução } & Parentesco & $\begin{array}{l}\text { Cuidados maternais e infantis/ } \\
\text { Planificação familiar }\end{array}$ \\
\hline & Abrigo/habitação & Higiene do meio \\
\hline Bem-estar corporal & Proteção & $\begin{array}{c}\text { Vacinação } \\
\text { Prevenção das doenças transmissíveis }\end{array}$ \\
\hline Segurança & Atividades & $\begin{array}{c}\text { Prevenção de acidentes e tratamentos } \\
\text { de ferimentos, cuidados com gravidez } \\
\text { (pré-natal) }\end{array}$ \\
\hline Movimento & Educação & $\begin{array}{c}\text { Educação para a saúde/ participação } \\
\text { comunitária }\end{array}$ \\
\hline Crescimento/Saúde & Higiene & $\begin{array}{l}\text { Fornecimento de medicamentos } \\
\text { essenciais }\end{array}$ \\
\hline \multicolumn{3}{|c|}{$\begin{array}{l}\text { Fonte: Vers une nouvelle civilization. In: BRELET, Claudine. Anthropologie de l'ONU, } \\
\text { 1995: p. } 185 .\end{array}$} \\
\hline
\end{tabular}

O Quadro III serve para mostrar o que Malinowski afirma ao dizer que a "saúde reenvia para todas as outras entradas" e que não existe uma "ubiqüidade de instituições e uma ausência de correlações unívocas entre necessidades biológicas e resposta institucional”. Segundo sua teoria, às necessidades biológicas correspondem necessidades secundárias ou derivadas, ou seja, instrumentais de uma institucionalização. Essas necessidades se manifestam através de "quatro grandes tipos de áreas de atuação" que ele classifica por ordem de 
complexidade crescente, família, grupo de idade, clā, equipe de cooperação, e que elas se definem em função do valor atribuído à codificação de normas comuns. Além delas, são definidos os oito componentes sobre os cuidados de saúde primários, obtendo-se o meio de "estratégias dos cuidados de saúde primárias" em relação às práticas médicas e sanitárias apropriadas a cada cultura. Essa estratégia sanitária constitui o resultado lógico da definição universal da saúde adotada pela Assembléia Mundial da Saúde em 1948.

Esclarecendo, sabe-se que o método proposto por Malinowski surgiu como proposta científica nos tempos da Colonização, e como instrumento de orientação para mediar as relações entre metrópoles e colônias na primeira fase da expansão capitalista e, segundo Brelet (1995), está sendo utilizado pela ONU como auxiliar no tratamento dos problemas atuais que envolvem a nova fase de expansão do capitalismo, a global.

Sobre esse aspecto, a globalização reflete uma espécie de reacomodação do mesmo processo iniciado com o Iluminismo. E, levando-se em consideração a assimetria e a reacomodação das relações sociais no plano internacional, a utilização da lógica positivista e fragmentada de uma proposição jurídica unificada frente às múltiplas realidades culturais, por si só, não consegue lograr resultados satisfatórios. Daí o desenvolvimento de uma visão antropológica complementar à proposta jurídica para, com o auxílio de ambas, identificar elos comuns capazes de afirmar tanto a existência de universalidade, proposta pelos princípios defendidos pelos Direitos Humanos, quanto a multiplicidade cultural, resultante das contingências físicas (materiais) e morais de cada sociedade.

Para a antropologia desenvolvida por Malinowski, é indispensável pensar as relações entre conjuntos e subconjuntos sociais, pois “le dynamisme et l'utilitarisme caracterísent tout le système: les institutions ne sont là que pour décupler la force, les facultés, le temps, impartis à chacun de nous pour rendre plus efficaces les efforts de l'homme" "15 (MALINOWSKI, 1963, p.22). Dessa maneira, pode-se afirmar que o dinamismo e o utilitarismo das instituiçôes que correspondem às necessidades de cada sociedade, quando "impactadas" pela introdução de "necessidades alheias" (formas culturais diferenciadas no atendimento às

\footnotetext{
${ }^{14}$ Utilitarismo. "doutrina ética segundo a qual o bem se identifica com o útil. Algumas expressões do utilitarismo já se encontram entre os sofistas da antiga Grécia, mas é com Jeremy Bentham (1748-1832) que se firma como um sistema filosófico. Para Bentham, toda felicidade está na obtenção do útil, ou seja, no afastar-se da dor e aproximarse o máximo possivel do prazer. Esse objetivo é defendido por Bentham não em termos de satisfação individual, mas em função da felicidade de todos. Outros importantes representantes do utilitarismo foram James Mill (1773-1836), historiador, filósofo e economista inglês; seu filho John Stuart Mill (1773-1836), também filósofo e economista; George Edward Moore (1873-1958), que defende um utilitarismo idealista" (SANDRONI, 1985, p. 444).

${ }^{15}$ Tradução: o dinamismo e o utilitarismo caracterizam todo o sistema: as instituições não existem senão para decuplicar a força, as faculdades, os tempos, repartidos a cada um dos indivíduos para render mais eficazes os esforços do homem.
} 
mesmas necessidades) à uma realidade cultural diferente, estas tendem a transformar a segunda num instrumento de assimilação ideológica, revertendo sua lógica e identidade originais, adaptando-as às necessidades precedentes ou substituindo um formato por outro. A título de exemplo, ao isolar o direito como instituição social, relacionando-o aos postulados do funcionalismo, este deve ser buscado antes no campo das relaçôes sociais do que nas normas consideradas a sua expressão. Com isso, a coerência social resulta das relações estabelecidas pelas necessidades comuns aos indivíduos, pois caso contrário, transforma-se em imposição, sanção ou ameaça advinda de uma autoridade exterior.

ParaSaid (1995), essas idéias de contraponto, entrelaçamento, integração cultural e identitárias não sugerem que se deva ter uma universalidade de visão, mas sim "considerar a dominação imperial e a resistência a ela como um processo dual, evoluindo rumo à descolonização, [consistindo] amplamente em se alinhar com o processo, e interpretar ambos os lados da disputa não só em termos hermenêuticos, mas também políticos" (SAID, 1995, p.322).

\subsection{Institucionalização e operacionalização do PNDH I e II}

Especificamente referindo o Brasil e os PNDHs I e II, sob o enfoque das preocupações empíricas, informações obtidas a respeito da promoção e proteção dos Direitos Humanos mostram que elas se encontram subsidiadas pela formulação e implementação de políticas públicas, fomentadas pela criação de programas e de órgãos estaduais concebidos sob a ótica dos referidos Planos. É o caso da criação da Secretaria de Estado dos Direitos Humanos, no âmbito do Ministério da Justiça, que possibilitou ao governo federal seu engajamento em açôes previstas pelas metas dos PNDHs I e II, incorporadas aos instrumentos de planejamento e orçamento do governo federal e concretizadas através de recursos financeiro assegurados nas Leis Orçamentárias Anuais, conforme determina o Plano Plurianual ${ }^{16}$ (PPA).

\footnotetext{
${ }^{16}$ Plano Plurianual. De acordo com Pereira (2003) , trata-se de uma técnica de elaboração e execução do orçamento público com ênfase para o planejamento e serve de instrumento de planejamento estratégico das ações do Governo. Surgiu através da Lei Complementar nÚ 101, de 2000 (LRF - Lei de Responsabilidade Fiscal), esbabelecendo: primeiro, normas de finanças públicas preocupadas com a responsabilidade na gestão fiscal e com a sua transparência, e, segundo: novos conteúdos à Lei Orçamentária Anual - LOA, além dos prescritos na Constituição Federal e na Lei nÚ 4320, de 1964. Segundo VAINER; ALBUQUERQUE; GARSON (2001), o Plano visa: orientar a ação governamental objetivando alcançar o desenvovimento econômico que propicie a promoção do bem-estar social; orientar o planejamento, em sintonia com a programação e o orçamento do Poder Executivo, obececendo aos princípios de regionalização da economia; definir diretrizes que deverão nortear a elaboração dos orçamentos fiscal e de investimentos, que possibilitem a redução das desigualdades regionais e sociais; ordenar e disciplinar a execução de despesas com investimntos que se reverterão em benefício para a sociedade.
} 
Desse modo, os resultados da elaboração e implantação dos PNDHs I e II, podem ser verificados entre os três níveis de governo e dos poderes Executivo, Legislativo e Judiciário, além das parcerias entre órgãos governamentais e entidades da sociedade civil. Dentre as principais preocupaçôes manifestas pelas áreas de atuação governamental e não governamental encontram-se os esforços empreendidos para o combate a todas formas de discriminação, a adoção de políticas de ação para a promoção da igualdade e o do combate à prática da tortura, o do combate à exploração sexual de crianças e adolescentes, assim como dos mecanismos de re-inserção social do adolescente em conflito com a lei. Enquanto o PNDH I enfatiza a garantia de proteção dos direitos civis, o PNDH II, incorpora ações específicas no campo da garantia do direito à educação, à saúde, à previdência social e assistência social, ao trabalho, à moradia, a um meio ambiente saudável, à alimentação, à cultura e ao lazer. No entanto, ambos apresentam propostas voltadas para a educação e sensibilização de toda a sociedade brasileira com vistas à construção e consolidação de uma cultura de respeito aos Direitos Humanos.

Na época da elaboração do PNDH II (1999), o então Presidente da República, Fernando Henrique Cardoso Governo, se mostrava animado ao verificar que o Brasil inaugurava uma nova era no campo das políticas sociais deixando para trás aquelas de cunho assistencialista e iniciando a construção de uma rede de proteção social, implementadas por programas voltados para a transferência direta de renda aos mais pobres, através da criação de condiçóes de acesso a bens e serviços.

Este esforço pode ser verificado através dos convênios firmados entre a Secretaria de Estado dos Direitos Humanos ${ }^{17}$, âmbito federal, e demais entidades existentes nos planos estaduais e municipais, onde são percebidas as concentrações de esforços e de atitudes políticas, respaldadas financeiramente, em áreas sociais selecionadas pelos PNDH I e II.

A seguir, serão apresentados dados correspondentes ao período de 1996 a 2002 sobre a transferências de recursos financeiros, efetuadas pelo Governo Federal, voltadas para a concretização de programas de apoio destinados basicamente ao atendimento das necessidades de deficientes físicos, crianças e adolescentes, mulheres, vítimas e testemunhas, combate à discriminação e criação de infra-estrutura para o funcionamento do sistema proposto pelos PNDH I e II.

\footnotetext{
${ }^{17}$ Os dados que foram utilizados na composição dos gráficos que serão adiante apresentados constam de um documento elaborado pela Secretaria de Estado dos Direitos Humanos, intitulado Convênios e foi acessado eletronicamente em 11.11.2003.
} 


\begin{tabular}{|c|c|}
\hline \multicolumn{2}{|c|}{$\begin{array}{c}\text { Convênios para implantação do PNDH }(1996 / 2002) \\
\text { Totais por Estado (R\$) }\end{array}$} \\
\hline Acre & $2.517 .291,73$ \\
\hline Alagoas & $5.245 .156,51$ \\
\hline Amazonas & $3.055 .124,55$ \\
\hline Amapá & $3.078 .587,04$ \\
\hline Bahia & $10.165 .586,61$ \\
\hline Ceará & $4.599 .077,62$ \\
\hline Distrito Federal & $10.773 .552,95$ \\
\hline Espírito Santo & $4.977 .163,00$ \\
\hline Goiás & $6.444 .036,00$ \\
\hline Maranhão & $3.112 .021,84$ \\
\hline Minas Gerais & $18.616 .506,40$ \\
\hline Mato Grosso do Sul & $4.821 .807,19$ \\
\hline Mato Grosso & $2.294 .598,55$ \\
\hline Pará & $6.173 .947,53$ \\
\hline Paraíba & $2.943 .041,61$ \\
\hline Pernambuco & $10.539 .950,23$ \\
\hline Piauí & $2.438 .967,54$ \\
\hline Paraná & $3.433 .224,09$ \\
\hline Rio de Janeiro & $22.687 .597,47$ \\
\hline Rio Grande do Norte & $4.617 .733,80$ \\
\hline Rondônia & $2.156 .797,53$ \\
\hline Roraima & $994.639,02$ \\
\hline Rio Grande do Sul & $9.551 .899,72$ \\
\hline Santa Catarina & $4.090 .044,60$ \\
\hline Sergipe & $2.049 .088,33$ \\
\hline São Paulo & $21.940 .038,90$ \\
\hline Tocantins & $2.606 .149,84$ \\
\hline Total Geral no Brasil & $175.923 .630,20$ \\
\hline
\end{tabular}




\begin{tabular}{|l|r|}
\hline \multicolumn{2}{|c|}{ Convênios para implantação do PNDH (1996/2002) } \\
Totais por região (R\$) \\
\hline NORTE (AC-AM-AP-PA-RO-RR-TO) & $20.582 .537,24$ \\
\hline NORDESTE (AL-BA-CE-MA-PB-PE-PI-RN-SE) & $45.710 .624,09$ \\
\hline CENTRO-OESTE (DF-GO-MS-MT) & $24.333 .994,69$ \\
\hline SUDESTE (ES-MG-RJ-SP) & $68.221 .305,77$ \\
\hline SUL (PR-RS-SC) & $17.075 .168,41$ \\
\hline TOTAL GERAL NO BRASIL & $175.923 .630,20$ \\
\hline
\end{tabular}

\section{DISTRIBUIÇÃO POR REGIÃO (R\$)}

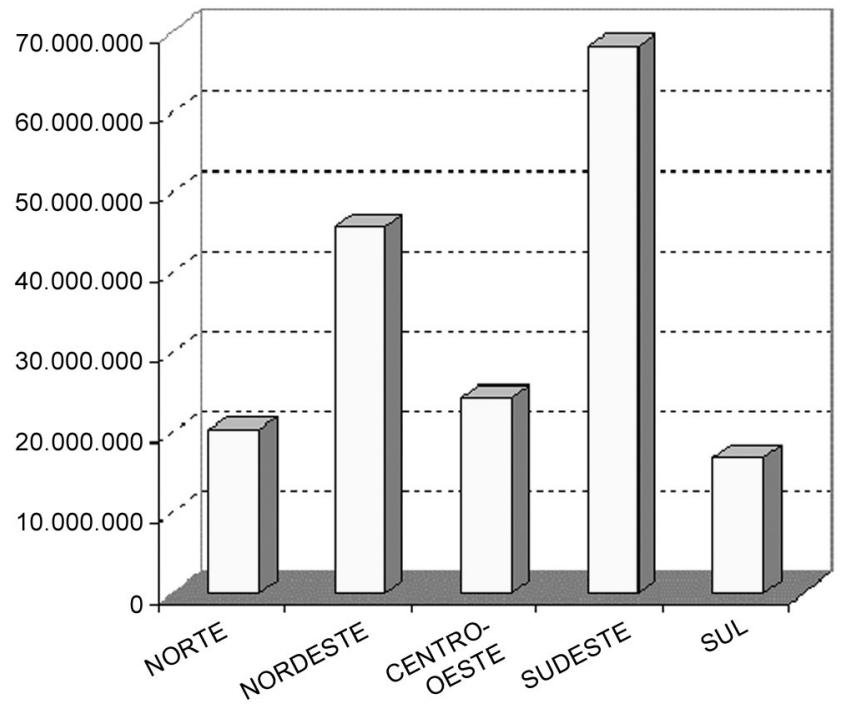




\begin{tabular}{|c|c|c|}
\hline \multicolumn{3}{|c|}{ Convênios para implantação do PNDH (1996/2002) } \\
\hline \multicolumn{3}{|c|}{ Totais per capita por região $(\mathrm{R} \$)$} \\
\hline NORTE & população $=12.900 .704$ & 1,60 \\
\hline NORDESTE & população $=47.741 .711$ & 0,96 \\
\hline CENTRO-OESTE & população $=11.636 .728$ & 2,09 \\
\hline SUDESTE & população $=72.412 .411$ & 0,94 \\
\hline SUL & população $=25.107 .616$ & 0,68 \\
\hline \multicolumn{3}{|c|}{ * valores aproximados } \\
\hline \multicolumn{2}{|c|}{ TOTAL GERAL NO BRASIL (R\$) } & $175.923 .630,20$ \\
\hline \multicolumn{2}{|c|}{ POPULAÇÃO TOTAL DO BRASIL EM 2.000} & 169.799 .170 \\
\hline \multicolumn{2}{|c|}{ TOTAL (R\$) per capita NO BRASIL } & 1,04 \\
\hline
\end{tabular}

\section{DISTRIBUIÇÃO PER CAPITA POR REGIÃO (R\$)}

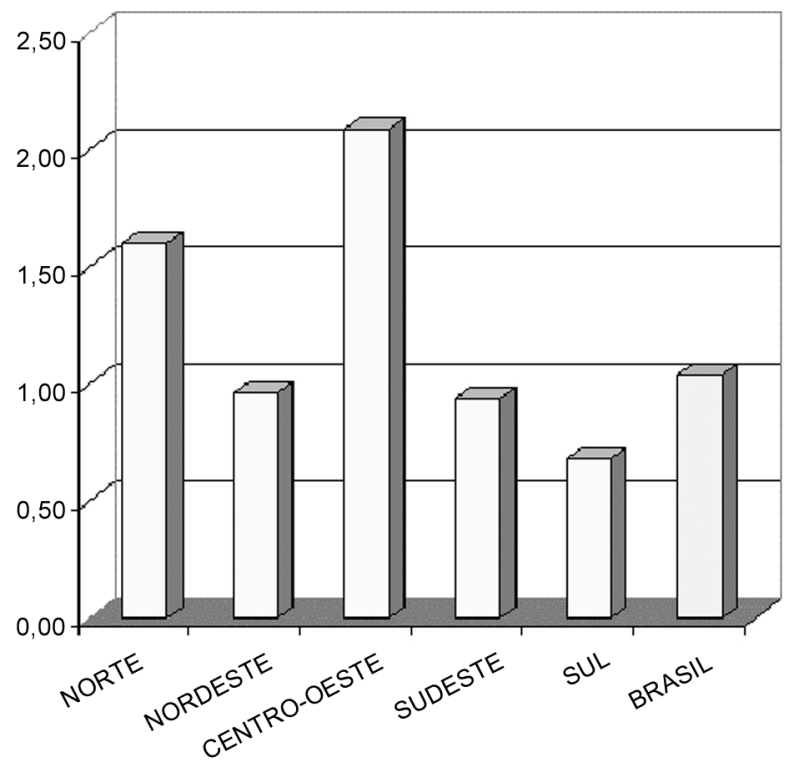


Os números apresentados mostram que a distribuição de verbas, acima de $\mathrm{R} \$$ 10.000.000,00 por Estado, contemplam em primeiro lugar o Rio de Janeiro seguido de São Paulo, Minas Gerais, Distrito Federal, Pernambuco e Bahia. No entanto, se for considerada a divisão das verbas a partir do critério de distribuição per capita, nota-se que a região Centro-Oeste (população de 11.636.728 indivíduos) foi priorizada ao obter um valor aproximado de R \$2, 09 para cada habitante; cabendo à Região Norte (população de 12.900.704 indivíduos) o valor de $\mathrm{R} \$ 1,60$; à região Nordeste (população de 47.741.711 pessoas) $\mathrm{R} \$ 0,96$; à região Sudeste (população de 72.412 .411 indivíduos); e, finalmente a região Sul (população de 25.107.616 indivíduos) R \$ 0,68. Vários foram os critérios adotados pelo Governo Federal para chegar a esses números, mas as prioridades foram dadas, respectivamente, às crianças e adolescentes, ao combate à discriminação, às vítimas e testemunhas, aos deficientes físicos, à infra-estrutura e às mulheres.

No caso dos convênios destinados às causas envolvendo a mulher, sabe-se da existência de muitas ONGs especializadas no tema, que nem sempre participam dos Convênios Federais por receberem apoio financeiro de outras fontes. Isto permite ao Governo concentrar recursos em outras áreas. Como exemplo, pode-se cietar o caso das Promotoras Legais Populares, iniciado em Porto Alegre pela ONG denominada Themis, originariamente formada por operadores do direito e, em São Paulo, gerido por mulheres, onde "formam-se grupos com mulheres moradoras de regióes da periferia de São Paulo e desenvolve-se um trabalho intenso de cursos que cobrem diversas áreas do direito" (SCHILLING, s.d., p.4), cujo objetivo é o de levar conhecimento sobre direitos às mulheres para que estas sirvam de mediadoras de conflitos em suas comunidades. Existem outras ONGs destinadas às ações para prevenção e superação de situações de práticas de violência contra as mulheres.

No caso dos convênios destinados aos deficientes físicos houve avanços, mas persistem as dificuldades em localizá-los para catalogação, principalmente em regiōes distantes do País, onde os registros dessas pessoas ainda é bastante precário em função das dificuldades de acesso e circulação dessas pessoas portadoras de deficiência física que, via-deregra, permanecem confinadas em suas casas. Sabe-se que a maioria dos Estados brasileiros contam, ainda que timidamente, com programas de atenção à pessoa portadora de deficiência, por exemplo, os de remoção de barreiras arquitetônicas em edifícios públicos e particulares. Os deficientes são caracterizados por mentais, físicos, de audiocomunicação, múltiplos, visuais e suas causas são devidas a doenças em geral, problemas congênitos, desnutrição, acidentes domésticos e esportivos, acidentes de trabalho, outros (guerras, desastres naturais e diagnósticos não identificados) e, para cada situação existe um trabalho específico a ser aplicado. 
A população idosa conta atualmente com a Delegacia do Idoso, a isenção de tarifas no transporte público, preferência no atendimento público e bancário e, em São Paulo, com o serviço telefônico SOS Idoso que informa, orienta e encaminha a população idosa que solicita seus serviços. E assim como os casos que foram apresentados, existem diversos programas e iniciativas voltadas para a prevenção ao uso das drogas e outras questôes como a AIDS, etc.

No entanto apesar da iniciativa governamental, observada através dos números apresentados, de distribuir renda por meio da implantação dos Direitos Humanos no Brasil, no contexto internacional, o caso brasileiro reflete uma situação preocupante quanto aos aspectos da falta de desenvolvimento social e econômico, do aumento da violência urbana, e, por conta desses fatos, a ONU tem utilizado e sugerido a adoção mundial de políticas de desenvolvimento econômico e social sustentado. Tais políticas dependem de uma série de medidas que, no caso brasileiro, podem ser observadas por meio dos diálogos mantidos nacional e internacionalmente com relação aos Direitos Humanos. Como exemplo, têm-se a construção da Constituição da República de 1988 e a criação do PNDH I e II, que inserem o País na discussão sobre a modernidade democrática, devendo ser operacionalizadas materialmente.

Nesse sentido e considerando o Brasil como um país de grandes dimensōes territoriais, com altos índices de desigualdade no contexto mundial e com grande contingente de pobreza e miséria foi criado, em 2001, o chamado Cadastro Único com o objetivo de tornar-se a base de dados para a implantação dos programas derivados do PNDH I e II, reunindo informaçōes sobre as famílias pobres, renda, consumo, estudo, profissão, característica do domicílio e presença de gestantes, idosos, mães amamentando e deficientes físicos. O Cadastro Único foi desenvolvido de forma descentralizada, cabendo às prefeituras dos Municípios a realização do cadastramento da população considerada mais carente.

Segundo Dantas (2004), a estratégia metodológica adotada pela descentralização do cadastramento tem suas vantagens ( $99 \%$ dos pobres já integram o sistema) e hoje o Cadastro Único é a base para a seleção dos beneficiários da Bolsa-Família, mas ser cadastrado não significa inclusão garantida no programa. Para ele, o governo atual estima que do Cadastro Único constam 9,8 milhōes de famílias, ou 39,5 milhões de pessoas, estimados em $84 \%$ da população carente com renda per capita familiar abaixo de meio salário mínimo, ou R\$130.

O Cadastro Único é um instrumento de política pública que serve para estabelecer e acompanhar metas sociais em todos o níveis de governo e deve ser complementado com dados como, por exemplo, aqueles apresentados pela pesquisa desenvolvida pelo IBGE - Instituto Brasileiro de Geografia e Estatísticas, em 2003, para identificar o orçamento familiar-POF, e, paralelamente, a agenda econômica ou fiscal deve insistir na prioridade 
da agenda social, sob pena do Estado perder seu sentido substantivo pela falta de capacidade de garantir efetivamente os direitos da população. Para isso, precisa aprimorar os instrumentos institucionais encarregados para tal, precisa adotar uma metodologia de monitoramento, avaliação e aprimoramento permanente dos PNDH I e II, através do Conselho Nacional dos Direitos Humanos (CNDH).

\section{Considerações Finais}

Tanto em nível nacional quanto internacional, o governo brasileiro assumiu uma postura clara no cenário mundial com relação ao fortalecimento dos organismos de proteção dos Direitos Humanos porque a globalização exige que instrituições supranacionais, como é o caso da ONU, sejam fortalecidas em suas metas de desenvolvimento sustentável, prevenção e cultura da paz. O Brasil percebeu que o desenvolvimento é a base mais segura para a paz e também a tarefa mais desafiadora que tem a enfrentar. Ele possui uma das legislações sociais mais avançadas da América Latina, mas sabe que o reconhecimento dos direitos não é suficiente para a garantia de sua efetivação. As necessidades essenciais ou básicas da população brasileira devem ser atendidas. Não se pode negar a implementação de vários projetos e iniciativas do Governo, mas ainda prevalecem ações isoladas, segmentadas, desarticuladas e pontuais, o que aponta para a necessidade de criação de um programa global de ações integradas em nível nacional. Em outras palavras, é preciso esclarecer a todos os brasileiros sobre a importância que representa a defesa dos Direitos Humanos para que, com isso, se conte com a participação comunitária nos projetos do governo.

Esta preocupação foi manifestada pelo Presidente da República Fernando Henrique Cardoso, quando do lançamento do PNDH I em seu pronunciamento, onde alertou para o fato de que,

...não obstante este conjunto expressivo de iniciativas, o passo de maior conseqüência certamente será o da adoção do Programa Nacional de Direitos Humanos. Este será, estou seguro, um marco de referência claro e inequívoco do compromisso do País com a proteção das mulheres e homens, crianças e idosos, das minorias e dos excluídos. Todos nós sabemos que não é possível extirpar, de um dia para o outro, com um passe de mágica, a injustiça, o arbítrio e a impunidade. Estamos conscientes de que o único caminho está na conjugação de uma ação obstinada do conjunto do Governo com a mobilização da sociedade civil. Este caminho, nós estamos decididos a trilhar, com determinação. O Programa Nacional dos Direitos Humanos foi elaborado a partir de ampla consulta à sociedade. Algumas dezenas de entidades e centenas de pessoas formularam sugestôes e críticas, participaram de debates e seminários. A maior parte das ações propostas 
neste importante documento tem por objetivo estancar a banalização da morte, seja ela no trânsito, na fila do pronto socorro, dentro de presídios, em decorrência do uso indevido de armas ou das chacinas de crianças e trabalhadores rurais. Outras recomendações visam a obstar a perseguição e a discriminação contra os cidadãos. Por fim, o Programa sugere medidas para tornar a Justiça mais eficiente, de modo a assegurar mais efetivo acesso da população ao Judiciário e o combate à impunidade. Estou convencido de que o Programa Nacional dos Direitos Humanos será o guia a pautar as nossas ações, do Governo e da sociedade, para construir o que é a aspiração maior de todos nós: um Brasil mais justo (CARDOSO, 1996: p.6).

\section{Bibliografia}

BRASIL. Convênios. Secretaria do Estado dos Direitos Humanos. Disponível em: <http.www.mj.gov.br/sedh/pndh/conv_sedh/convenio>. Acesso em: 11.11.2003. Presidência da República. Uma estratégia de desenvolvimento social. Brasília, Presidência da República, 1996.

BRELET, Claudine. Anthropologie de l'ONU. Utopie et Fundation. Paris: Editions L'Harmattan, 1995.

CARDOSO, Fernando Henrique. Prefácio. Programa Nacional de Direitos Humanos. Brasília: Presidência da República, Secretaria de Comunicação Social, Ministério da Justiça, 1996.

DANTAS, Fernando. Bolsa-Família. Brasil não consegue mapear seus pobres. Caderno Nacional, OESP, 26.09.2004, p. A16.

KANT, Immanuel. Idéia de uma história universal de um ponto de vista cosmopolita. São Paulo: Martins Fontes, 2003.

LALANDE, André. Vocabulário técnico e crítico da filosofia. São Paulo: Martins Fontes, 1999.

LALLEMENT, Michel. História das idéias sociológicas. De Parsons aos contemporâneos. Petrópolis: Vozes, 2004.

LEFORT, Claude. L invention democratique. Les limites de la domination totalitaire. France: Fayard, 1994.

MALINOWSKI, Bronislaw. Les argonautes du Pacific occidental. Paris: Gallimard, 1963. Antropología. In: DURHAN, E. R.(Org.); FERNANDES, Florestan (Coord). Grandes cientistas sociais. São Paulo: Ática, 1986. . apud BRELET, Claudine. Anthropologie de l'ONU. Utopie et Fundation. Paris: Editions L'Harmattan, 1995. 
. apud LALLEMENT, Michel. História das idéias sociológicas. De Parsons aos contemporâneos. Petrópolis: Vozes, 2004.

MARX, Karl. A questão judaica. 4. ed. São Paulo: Centauro, 2003.

MORIN, Edgar; KERN, Anne Brigitte. Terra pátria. 4. ed. Porto Alegre: Sulina, 2003.

OUTHWAITE, William et. al. Dicionário do pensamento social do século XX. Rio de Janeiro: Jorge Zahar Editor, 1996.

PEREIRA, José Matias. Finanças públicas. 2. ed. São Paulo: Atlas, 2003.

PIOVESAN, Flávia. Temas de direitos humanos. 2. ed. São Paulo: Max Limonad, 2003.

RESENDE, Paulo-Edgar Almeida. Da justificação à proteção da universalidade dos direitos humanos. Humanidades, Brasília, Universidade de Brasília, n. 39, s.d.

ROSLER, Andrés B. Derecho natural y sociología. Tönnies y la filosofia política del teorema Comunidad y Sociedad. Buenos Aires: Centro Editor de América Latina. 1993.

SAID, Edward W. Cultura e imperialismo. São Paulo: Cia. das Letras, 1995.

SANDRONI, Paulo. Dicionário de economia. São Paulo: Abril Cultural, 1985. (Coleção Os Economistas).

SCHILLING, Flávia. Da declaração à ação. Subsídios para o trabalho em educação em Direitos Humanos. Projeto de Pesquisa. EDF-FE; USP, s.d.

VAINER, Ari; ALBUQUERQUE, Josélia; GARSON, S. L. Plano plurianual. Manual de elaboração. Brasília: Ministério do Planejamento, Orçamento e Gestão, 2001. 